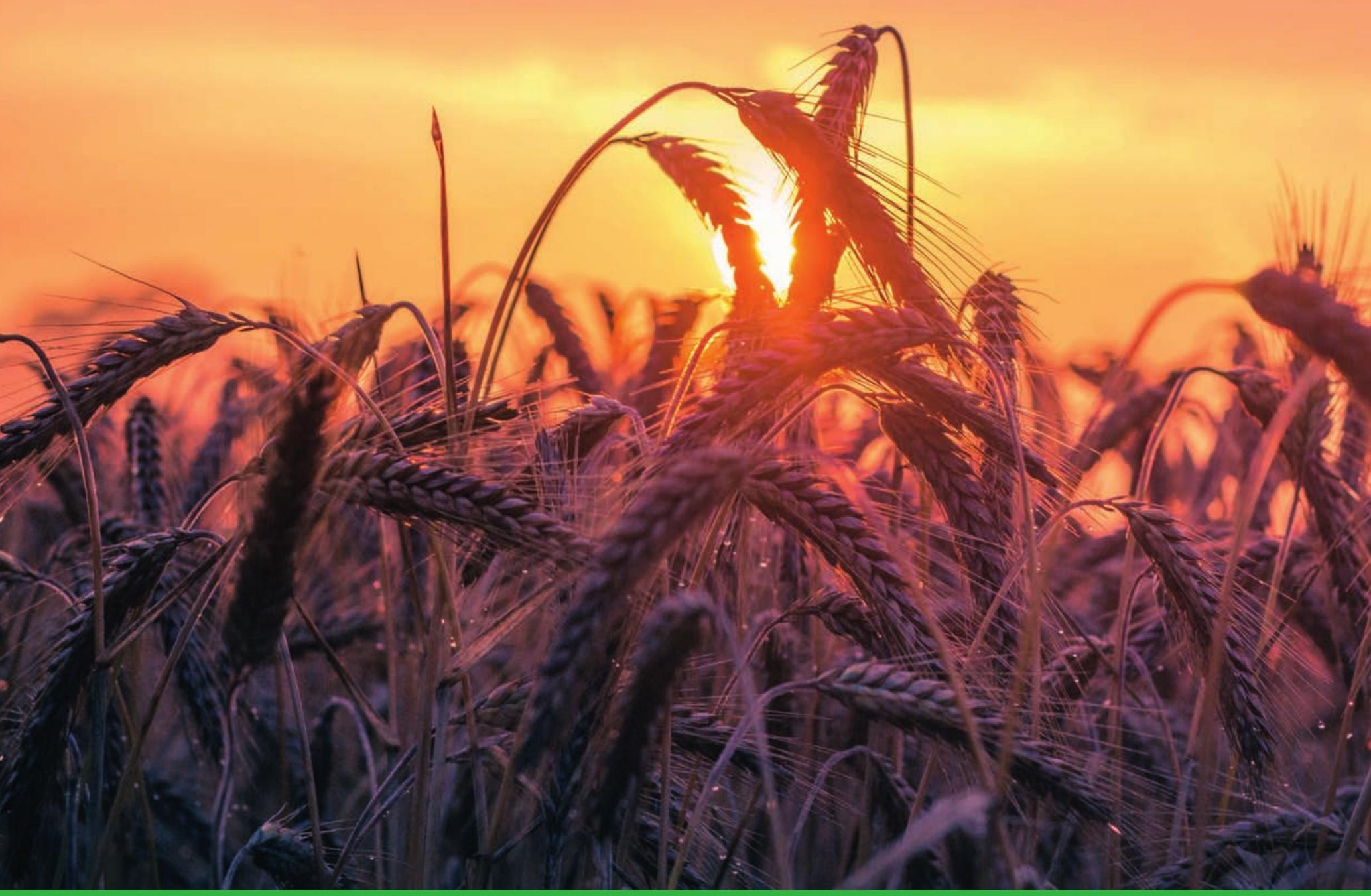

Onderzoek aan lucht-vloeistof mengdoppen Airtec NAP06LD 80 Groen en Airtec NAP06LD 80 Blauw voor classificatie op basis van driftgevoeligheid

H.J. Holterman, D.C. de Hoog, J.C. van de Zande 



\section{Onderzoek aan lucht-vloeistof mengdoppen Airtec NAP06LD 80 Groen en Airtec NAP06LD 80 Blauw voor classificatie op basis van driftgevoeligheid}

H.J. Holterman, D.C. de Hoog, J.C. van de Zande

Dit onderzoek is in opdracht van Gebr. Weststrate bv, uitgevoerd door de Stichting Wageningen Research (WR), business unit Agrosysteemkunde, onder projectnummer 3710470800. 
Holterman, H.J., D.C. de Hoog, J.C. van de Zande, 2022. Onderzoek aan lucht-vloeistof mengdoppen Airtec NAP06LD 80 Groen en Airtec NAP06LD 80 Blauw voor classificatie op basis van driftgevoeligheid. Wageningen Research, Rapport WPR-1097. 26 blz.; 5 fig.; 9 tab.; 18 ref.

Dit rapport is gratis te downloaden op https://doi.org/10.18174/557370

In deze studie zijn de lucht-vloeistofmengdoppen Airtec NAP06LD 80 onderzocht om hun driftgevoeligheid vast te stellen voor classificatie bij gebruik in neerwaartse toedieningen. Met name het gebruik bij een dopafstand van 0,25 m en verlaagde spuitdophoogte is onderzocht. Er zijn verschillende configuraties onderzocht door te variëren in vloeistof- en luchtdruk en spuitdophoogte. Van deze configuraties is eerst op een spuitbord vastgesteld of zij een voldoende gelijkmatige verdeling zouden geven, dat wil zeggen een voldoende lage variatiecoëfficiënt $(\mathrm{VC}<10 \%)$. Vervolgens zijn metingen gedaan van de druppelgrootteverdelingen. Op basis van een voldoende laag aandeel kleine druppels $\left(\mathrm{V}_{100}\right)$ zouden negen combinaties in aanmerking kunnen komen voor de status driftarm (DRD50). Twee combinaties daarvan zijn verder onderzocht met het IDEFICS driftmodel, om te onderzoeken of ze in aanmerking zouden kunnen komen voor een hogere classificatie als driftreducerend doptype. Van die twee bleek een combinatie een driftreductie van meer dan $75 \%$ op te leveren, waarmee een indeling in klasse DRD75 mogelijk zou zijn.

De testresultaten gaven aan dat de Airtec NAP06LD 80 Groen en Airtec NAP06LD 80 Blauw bij diverse combinaties van vloeistof- en luchtdruk de status driftarm (DRD50) zou kunnen behalen. De Airtec NAP06LD 80 Blauw bij een vloeistofdruk van $300 \mathrm{kPa}$ en een luchtdruk van $60 \mathrm{kPa}$ zou in aanmerking kunnen komen voor de klasse DRD75. Deze bepalingen zijn gedaan bij een spuitdophoogte van $0,50 \mathrm{~m}$ volgens het geldende meetprotocol voor het vaststellen van de driftreductie van spuitdoppen.

Trefwoorden: druppelgrootte, drift, driftreductie, classificatie, simulatie

(C) 2022 Wageningen, Stichting Wageningen Research, Wageningen Plant Research, Business unit Agrosysteemkunde, Postbus 16, 6700 AA Wageningen; T 03174807 00; www.wur.nl/plant-research

KvK: 09098104 te Arnhem

VAT NL no. 8113.83.696.B07

Stichting Wageningen Research. Alle rechten voorbehouden. Niets uit deze uitgave mag worden verveelvoudigd, opgeslagen in een geautomatiseerd gegevensbestand, of openbaar gemaakt, in enige vorm of op enige wijze, hetzij elektronisch, mechanisch, door fotokopieën, opnamen of enige andere manier zonder voorafgaande schriftelijke toestemming van Stichting Wageningen Research.

Stichting Wageningen Research is niet aansprakelijk voor eventuele schadelijke gevolgen die kunnen ontstaan bij gebruik van gegevens uit deze uitgave.

Rapport WPR-1097

Foto omslag: licentievrije foto van pexels.com 


\section{Inhoud}

Woord vooraf $\quad 5$

$\begin{array}{ll}\text { Samenvatting } & 7\end{array}$

$\begin{array}{ll}\text { Summary } & 9\end{array}$

$\begin{array}{lrr}1 & \text { Inleiding } & 11\end{array}$

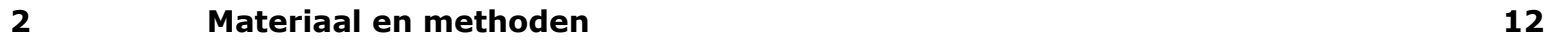

2.1 Selectie van spuitboomconfiguraties 12

2.2 Meetmethodiek druppelgrootte 13

$\begin{array}{ll}2.3 \text { Modelberekeningen } & 15\end{array}$

$\begin{array}{ll}2.4 & \text { Indeling in driftreductieklassen }\end{array}$

$\begin{array}{llr}3 & \text { Meetresultaten } & 17\end{array}$

$\begin{array}{lll}3.1 & \text { Vloeistofverdeling van spuitboomconfiguraties } & 17\end{array}$

$\begin{array}{lll}3.2 & \text { Vloeistofafgifte } & 17\end{array}$

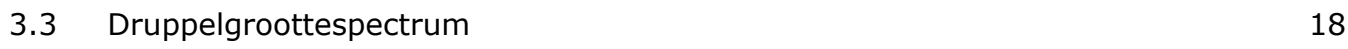

$\begin{array}{ll}3.4 & \text { Driftdepositie en dopclassificatie }\end{array}$

$\begin{array}{lrr}4 & \text { Conclusie } & 20\end{array}$

$\begin{array}{ll}\text { Literatuur } & 21\end{array}$

$\begin{array}{lll}\text { Bijlage } 1 & \text { Overzicht metingen van druppelgroottes } & 22\end{array}$ 



\section{Woord vooraf}

Dit onderzoek naar de driftreducerende eigenschappen van Airtec NAP06LD 80 spuitdoppen met twee typen restrictors voor gebruik op veldspuiten in akkerbouwmatig geteelde gewassen is uitgevoerd in opdracht van Gebr. Weststrate bv. Het onderzoek is begeleid door dhr. A. Weststrate. 


\section{Samenvatting}

In deze studie zijn de lucht-vloeistofmengdoppen Airtec NAP06LD 80 onderzocht om hun driftgevoeligheid vast te stellen voor classificatie bij gebruik in neerwaartse toedieningen. Met name het gebruik bij een dopafstand van 0,25 m en verlaagde spuitdophoogte is onderzocht. Er zijn verschillende configuraties onderzocht door te variëren in vloeistof- en luchtdruk en spuitdophoogte. De Airtec NAP06LD 90 bevat een restrictor (doseerplaatje) in de dop. De studie is uitgevoerd met twee restrictors, aangeduid als 35 ('groen') en 40 ('blauw'). Van de verschillende configuraties is eerst op een spuitbord vastgesteld of zij een voldoende gelijkmatige vloeistofverdeling zouden geven, dat wil zeggen een voldoende lage variatiecoëfficiënt (VC<10\%). Vervolgens zijn metingen gedaan van de druppelgrootteverdelingen. Op basis van een voldoende laag aandeel kleine druppels $\left(\mathrm{V}_{100}\right)$ zouden negen combinaties in aanmerking kunnen komen voor de status driftarm (DRD50). Twee combinaties daarvan zijn verder onderzocht met het IDEFICS driftmodel, om te onderzoeken of ze in aanmerking zouden kunnen komen voor een hogere classificatie als driftreducerend doptype. Van die twee bleek een combinatie een driftreductie van meer dan $75 \%$ op te leveren, waarmee een indeling in klasse DRD75 mogelijk zou zijn.

De testresultaten gaven aan dat de Airtec NAP06LD 80 Groen en Airtec NAP06LD 80 Blauw bij diverse combinaties van vloeistof- en luchtdruk de status driftarm (DRD50) zou kunnen behalen. De Airtec NAP06LD 80 Blauw bij een vloeistofdruk van $300 \mathrm{kPa}$ en een luchtdruk van $60 \mathrm{kPa}$ zou in aanmerking kunnen komen voor de klasse DRD75. Deze bepalingen zijn gedaan bij een spuitdophoogte van $0,50 \mathrm{~m}$ volgens het geldende meetprotocol voor het vaststellen van de driftreductie van spuitdoppen. 


\section{Summary}

In this study twin fluid nozzles of types Airtec NAP06LD 80 were investigated to establish their drift reduction potential for possible classification for downward application techniques. Particularly their use with nozzle distance of $0.25 \mathrm{~m}$ and reduced boom height was of interest. Various configurations were investigated by varying the liquid pressure, air pressure and boom height. The Airtec NAP06LD 90 contains a restrictor (dosing diaphragm) inside the nozzle. This study involved two restrictor types, identified as 35 ('green') en 40 ('blue'). These configurations were tested first on a horizontal patternator to evaluate the evenness of the spray liquid distribution, by quantifying the coefficient of variation (CV) and selecting the situations where $\mathrm{CV}<10 \%$. Subsequently, drop size measurements were carried out. Nine combinations gave a sufficiently low fraction of small drops $\left(\mathrm{V}_{100}\right)$ and therefore could qualify for a classification as low-drift nozzles. Two of these combinations were investigated further using the IDEFICS spray drift model to quantify their potential for a possibly higher drift reduction classification. One of these turned out to give a drift reduction of more than $75 \%$.

The test results indicated that the Airtec NAP06LD 80 Green and Airtec NAP06LD 80 Blue nozzle types could qualify as low-drift nozzles (DRN50) for various combinations of liquid and air pressures. The Airtec NAP06LD 80 Blue nozzle type with liquid pressure of $300 \mathrm{kPa}$ and air pressure of $60 \mathrm{kPa}$ could qualify for a DRN75 classification. These determinations were carried out for a sprayer boom height of $0.50 \mathrm{~m}$ following the current Dutch protocol for establishing drift reductions of nozzles. 


\section{$1 \quad$ Inleiding}

Het Activiteitenbesluit Milieubeheer (I\&M, 2012, 2017a) bepaalt dat bij bespuitingen van een gewas met veldspuitapparatuur het gehele veld bespoten moet worden met een $75 \%$ driftreducerende techniek (DRT75). Bijvoorbeeld een standaard veldspuit uitgerust met 75\% driftreducerende doppen (DRD75). In de "Beoordelingssystematiek emissiereducerende maatregelen open teelt" (TCT, 2017) en de daarin beschreven testmethode "Meetprotocol vaststellen driftreductie spuitdoppen-versie 15 maart 2021" (I\&W, 2021; hierna kortweg aangeduid als 'meetprotocol') worden de eisen beschreven waaraan de spectra van spuitdoppen moeten voldoen om als driftarm te worden aangemerkt. Ook is hierin de toe te passen meetmethode vastgelegd. Driftarme doppen kunnen onderling behoorlijk verschillen in werkelijke driftreductie. Door de Technische Commissie Techniekbeoordeling (TCT, 2021a) worden spuitdop-druk combinaties daarom ingedeeld in driftreductieklassen (DRD50, DRD75, DRD90, DRD95) voor gebruik in de verschillende driftreducerende technieken (DRT; TCT, 2021b) en ter bepaling van de teeltvrije zone bij intensief gespoten gewassen.

Dit rapport beschrijft een onderzoek naar de lucht-vloeistofmengdoppen van Airtec, doptypen NAP06LD 80. Bij dit doptype wordt in de spuitdop de spuitvloeistof gemengd met perslucht, waarbij een doseerplaatje in de dop de menging en afgifte beïnvloedt. Het lucht-vloeistofmengsel wordt vervolgens naar buiten geperst en tegen een RVS ketsdop gericht, waarna een waaiervormige spuitkegel ontstaat. Er zijn verschillende types doseerplaatjes (of 'restrictors'), te herkennen aan hun kleur. In dit onderzoek zijn groene en blauwe restrictors gebruikt (Figuur 1). De geteste spuitdoppen zijn daarom voor het gemak aangeduid als Airtec Groen en Airtec Blauw, naar de kleur van de restrictor. De doppen hebben een aansluiting voor de spuitvloeistof en voor perslucht. Vloeistofdruk en luchtdruk moeten afzonderlijk ingesteld worden en hebben samen een effect op de verdeling van de druppelgroottes. De opdrachtgever heeft een groot aantal combinaties van vloeistofdruk en luchtdruk getest en de vloeistofverdeling daarvan op een spuitbord bepaald (ISO5682-1, 2014; ISO5682-2; 2017). De combinaties die voldoende perspectief boden, zijn verder onderzocht wat betreft druppelgrootteverdeling en een bepaling van de mogelijk te bereiken driftreductie. Dit betrof de combinaties met een variatiecoëfficiënt kleiner dan $10 \%$ in de verdeling op het spuitbord (volgens ISO16122-2, 2015; en overeenkomstig het DRD meetprotocol, I\&W, 2021). Daarbij zijn voor enkele instellingen van de dopafstand en spuitdophoogte van een veldspuit voor gebruik in akkerbouwmatig geteelde gewassen berekeningen uitgevoerd met het driftmodel IDEFICS (Holterman et al., 1997). De methodiek voor de bepaling van driftreducties is beschreven door Porskamp et al. (1999), ISO22369 (2006) en in het bovengenoemde meetprotocol (I\&W, 2021).

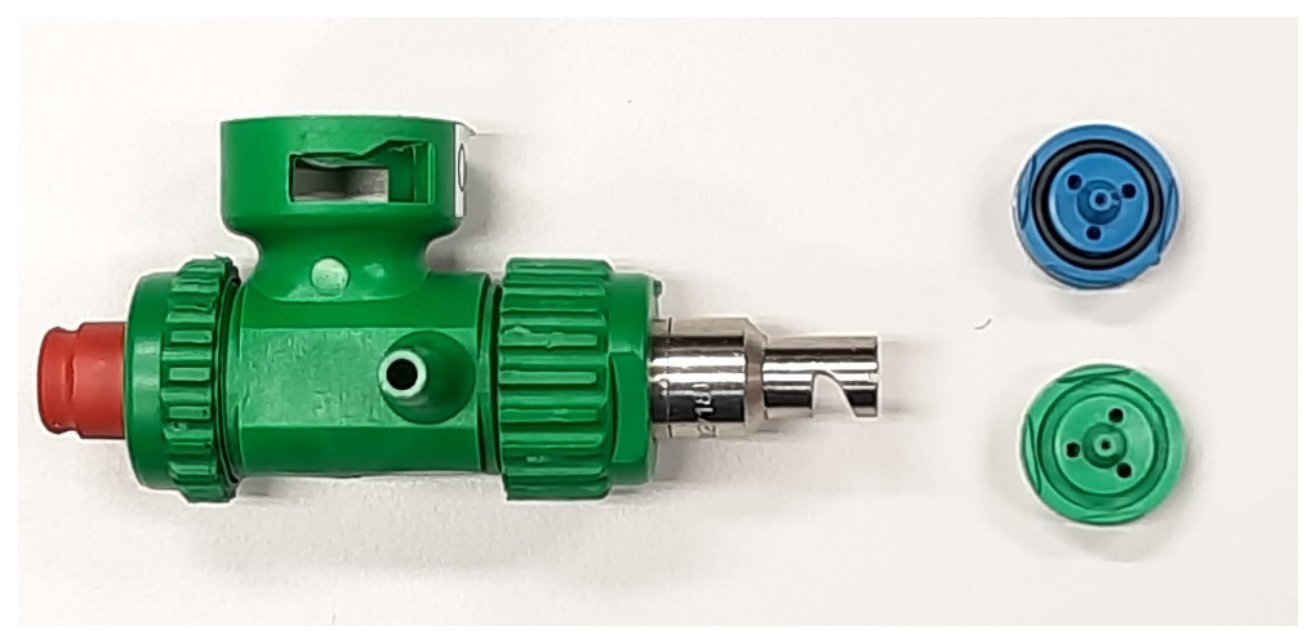

Figuur 1 Doptype Airtec NAP06LD 80 met RVS ketsdop en groene of blauwe restrictor. 


\section{$2 \quad$ Materiaal en methoden}

Van de doptypes Airtec NAP06LD 80 Groen en Airtec NAP06LD 80 Blauw (zie Figuur 1) werden het druppelgroottespectrum en de druppelsnelheden bepaald met behulp van de optische methode phasedoppler anemometrie (PDA) bij vloeistofdrukken 300, 400 en 500 kPa en luchtdrukken 60, 70, 80 en $100 \mathrm{kPa}$. Ook het druppelgroottespectrum van de grensdop Fijn/Midden voor neerwaartse toediening (F/M; Lurmark 31-03-F110 bij een spuitdruk van $300 \mathrm{kPa}$ ) van de klassenindeling volgens de British Crop Protection Council (BCPC, Southcombe et al., 1997) is op soortgelijke wijze gemeten; deze referentiedop wordt verder aangeduid als BCPC-F/M. Op termijn zal deze referentiedop vervangen worden door een ander spuitdoptype van dezelfde F/M klassegrens (Teejet TP 11003 SS bij 300 kPa, naar ISO 25358:2018); deze dop wordt aangeduid als ISO-F/M. Deze laatste dop is daarom ook meegenomen in de metingen, ook al is deze nog niet van belang voor de huidige beoordeling van de te testen doptypen.

Als spuitvloeistof werd leidingwater toegepast. De resulterende spectra werden gebruikt in het simulatiemodel IDEFICS (versie 0.434; Holterman et al., 1997) om de verwachte drift naar een standaardsloot te berekenen voor een gestandaardiseerde volvelds bespuiting. De evaluatiestrook voor driftdepositie komt overeen met de positie van het wateroppervlak; dit is 1,625-2,625 m vanaf de gewasrand. De simulaties met de onderzochte doptypen werden uitgevoerd voor een dopafstand van $0,50 \mathrm{~m}$ of een dopafstand van $0,25 \mathrm{~m}$. In alle situaties, dus zowel voor de te testen doppen als voor de referentiedoppen, werd de buitenste spuitdop op 0,50 m binnen de gewasrand geplaatst. Daarmee komt de evaluatiestrook op 2,125-3,125 m vanaf de buitenste dop te liggen (zie ook Figuur 5).

Recent is het meetprotocol voor driftreducerende doppen aangepast voor doppen met kleinere tophoek $\left(80-90^{\circ}\right)$, waarmee deze doppen getest mogen worden bij dopafstand van 0,25 $\mathrm{m}$ en een spuitdophoogte 0,50 m (I\&W, 2021). Het meetprotocol schrijft echter nog wel voor dat de buitenste dop zich op 0,50 m vanaf de gewasrand moet bevinden.

Driftdepositie wordt uitgedrukt als percentage van de uitgebrachte dosering per oppervlakte-eenheid. Aan de hand van de berekende drift van de BCPC-F/M referentiedop en de geteste combinaties met de Airtec-doppen werden de dop-drukcombinaties beoordeeld naar het systeem van driftreductieklassen (volgens ISO22369 t.o.v. de BCPC-F/M grensdop) volgens het classificatiesysteem van de TCT (TCT, 2017).

\section{$2.1 \quad$ Selectie van spuitboomconfiguraties}

Vloeistofverdelingen en VC-bepalingen zijn uitgevoerd door de opdrachtgever. Daarbij is gebruik gemaakt van een AAMS spuitbord (Figuur 2). Op dit spuitbord is de vloeistofverdeling gemeten voor verschillende combinaties van spuitdophoogte $(0,30,0,35,0,40$ en 0,50 m) en dopafstand $(0,25$ en $0,50 \mathrm{~m}$ ) voor de doptypen Airtec Groen en Airtec Blauw bij verschillende combinaties van vloeistof- en luchtdruk. Geen van de combinaties met dopafstand 0,50 m bleek een VC $<10 \%$ te hebben en deze combinaties zijn verder niet onderzocht. Daarnaast werd de toegepaste luchtdruk gevarieerd tussen 40 en $100 \mathrm{kPa}$ bij diverse vloeistofdrukken tussen 300 en $500 \mathrm{kPa}$. Ook hierbij voldeden sommige combinaties niet aan de eis van VC $<10 \%$ en werden uitgesloten van verder onderzoek. De instellingen van combinaties waarvoor wel VC $<10 \%$ bepaald is, staan in Tabel 1 in par.3.1, samen met de bijbehorende VC. 


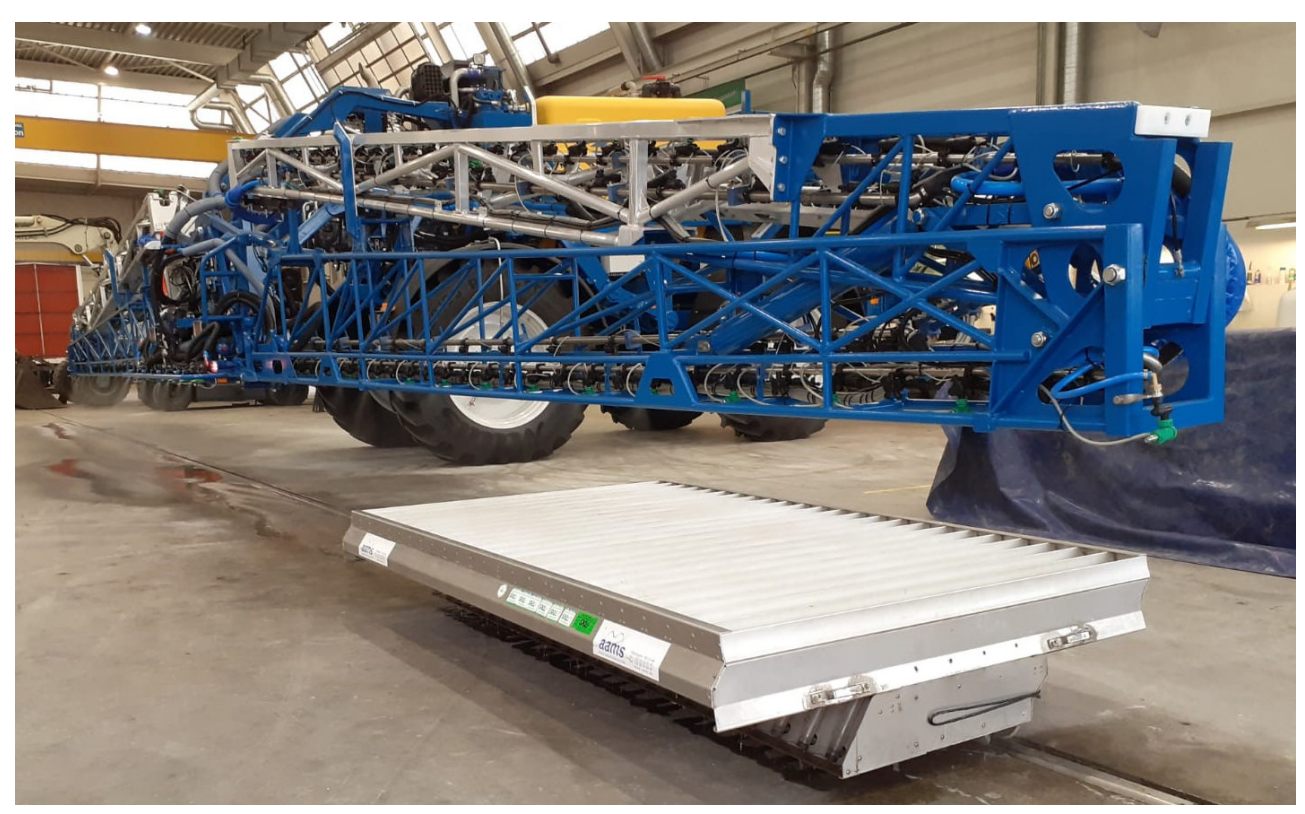

Figuur 2 Verdelingsmetingen bij opdrachtgever met behulp van AAMS spuitbord (foto Gebr. Weststrate bv).

Combinaties die op het spuitbord een variatiecoëfficiënt (VC) lager dan $10 \%$ opleverden, werden eerst beoordeeld op basis van de fractie druppels kleiner dan $100 \mu \mathrm{m}\left(\mathrm{V}_{100}\right)$, bepaald met de PDPA volgens de procedure zoals hieronder beschreven. Indien de $V_{100}$ kleiner is dan de helft van de $V_{100}$ van de BCPC-F/M, kan dit doptype bij de geteste druk aangemerkt worden als driftarm, overeenkomend met de DRD50-klasse (I\&W, 2021). Indien van een dop-drukcombinatie de $\mathrm{V}_{100}$ te groot was om als driftarm aangemerkt te kunnen worden, werd verder onderzoek met deze dop-drukcombinatie niet uitgevoerd. Voor dop-drukcombinaties die bij een eerste analyse kans leken te maken op een hogere klasse (namelijk DRD75) werden aanvullende simulaties met het IDEFICS driftmodel uitgevoerd om driftdeposities en driftreducties te bepalen voor een volvelds bespuiting.

Van 10 exemplaren van de te onderzoeken doppen is de vloeistofafgifte bepaald bij één combinatie van vloeistof- en luchtdruk (resp. 300 en $60 \mathrm{kPa}$ ). Uit deze waarden is de mediaan bepaald om vervolgens de 3 doppen te kunnen selecteren, waarvan de afgifte het dichtst bij de mediaan lag. Deze procedure hoeft slechts voor één drukcombinatie te worden toegepast, omdat bij andere combinaties de volgorde van doppen (qua afgifte) gelijk is en dus tot dezelfde keuze van 3 doppen zal leiden. Van de geselecteerde 3 doppen werden vervolgens het druppelgroottespectrum en druppelsnelheden bepaald met een Phase Doppler Particle Analyzer (PDPA, TSI). De spuitvloeistof hierbij was leidingwater met een temperatuur van $20^{\circ} \mathrm{C}$. De meetruimte werd ingesteld op een temperatuur van $20^{\circ} \mathrm{C}$ en een relatieve luchtvochtigheid van $70 \%$

Bij de metingen van het druppelgroottespectrum beschreef de doppositie een patroon van 11 parallelle banen (Figuur 3). De lengte van de banen en hun onderlinge afstand werden per situatie zodanig ingesteld, dat het banenpatroon het totale spuitpatroon goed afdekte. De snelheid waarmee het banenpatroon werd doorlopen, werd daarbij zodanig afgesteld, dat ten minste 10000 druppels per meting werden gemeten. Voor zowel de Airtec-doppen als de referentie- en grensdoppen was de dophoogte 0,35 m boven het meetvlak. De meethoogte boven de vloer bedroeg 0,70 $\mathrm{m}$. Ten slotte werd de tophoek van de spuitkegel bij elke dop-drukcombinatie geometrisch bepaald. De tips van de Airtec-doppen zijn zogenaamde ketsdoppen, waarbij gewoonlijk een spuitkegel ontstaat die iets schuin naar achteren gericht is. Deze 'kantelhoek' bleek ca. $25^{\circ}$ te zijn. Bij de druppelgroottemetingen moest de dophouder over dezelfde hoek gedraaid worden, om de spuitkegel tijdens deze metingen verticaal te houden (zie Figuur 4). 


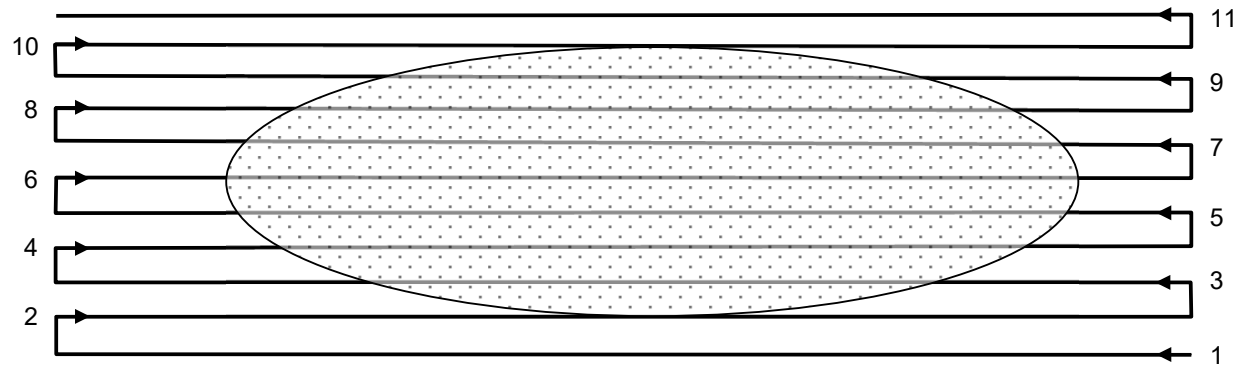

Figuur 3 Patroon van de banen voor het scannen van de druppelgrootteverdeling in een horizontaal vlak 0,35 m onder een spuitkegel van een spleetdop. De baanlengte en de onderlinge baanafstand werden aangepast aan de spuitpatronen van de te meten doppen. Baan 6 is de middelste baan loodrecht onder de dop.

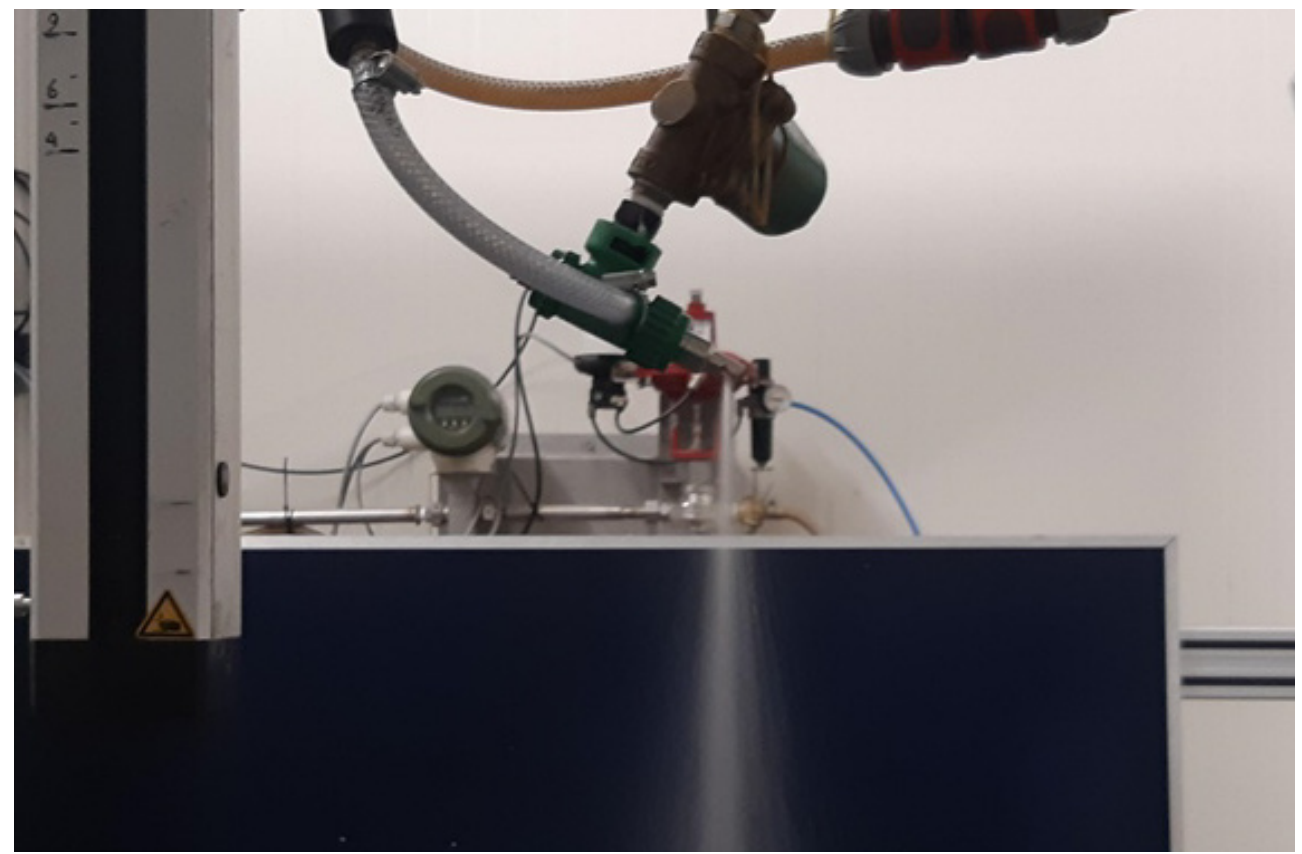

Figuur 4 Gekantelde dophouder om spuitkegel van Airtec-doppen verticaal te richten tijdens de PDPA-metingen. De kantelhoek bedroeg ca. $25^{\circ}$.

Van elk van de drie geselecteerde doppen werd de druppelgroottebepaling in drievoud uitgevoerd. Per meetdag werden ook metingen uitgevoerd voor de referentiedop BCPC-F/M en de nieuwe referentiedop ISO-F/M.

Voor de bepaling van het snelheidsverloop van druppels in de spuitkegel, zijn afzonderlijke metingen uitgevoerd met de PDPA. Deze puntmetingen zijn uitgevoerd in het centrum van de spuitkegel op 4, 6, $9,12,15,20,25$ en $30 \mathrm{~cm}$ midden onder de dop. De meetresultaten bestonden uit de verticale snelheid en de diameter van elke gedetecteerde druppel. Hieruit werd de gemiddelde druppelsnelheid afgeleid als functie van druppelgrootte en afstand onder de dop. Deze resultaten werden vervolgens gebruikt om voor het IDEFICS driftmodel de entrainment te bepalen (de luchtstromingen in de spuitkegel) en de beginsnelheid van druppels bij het verlaten van de spuitdop.

De PDPA was tijdens de metingen als volgt ingesteld:

- Laservermogen in meetpunt $25 \mathrm{~mW}$

- Focus frontlens transmitter $1000 \mathrm{~mm}$

- Focus frontlens detector $1000 \mathrm{~mm}$

- Expander/contractor contractor

- Detectiehoek $40^{\circ}$

- Detectorspanning 
- Signaaldrempel

- Meetbereik

- Diameter resolutie

- Probe Volume Correction
$50 \mathrm{mV}$

$5-1250 \mu \mathrm{m}$

$2,4 \mu \mathrm{m}$

ja

Het laservermogen werd vooraf aan elke meting gecontroleerd en zo nodig bijgesteld. Ook de inkoppeling van de laserstralen in de glasvezels in de zogenaamde 'fiber-drive' werd voorafgaande aan elke meting gecontroleerd. Deze mechanische koppeling is zeer gevoelig voor temperatuurveranderingen en trillingen. Daarbij was steeds het nuttig laservermogen ter plaatse van de feitelijke druppelmetingen leidend: dit vermogen werd constant gehouden op de genoemde waarde van $25 \mathrm{~mW}$.

De resultaten van de druppelgroottemetingen worden gepresenteerd als de $D_{\mathrm{V} 10}, D_{\mathrm{V} 50}, D_{\mathrm{V} 90}, V_{100}$ en $\mathrm{v}_{\mathrm{gem}}$. Hieronder volgt een korte toelichting op deze begrippen:

- $\mathrm{D}_{\mathrm{v} 10}[\mu \mathrm{m}] ; 10 \%$ van het volume bestaat uit druppels die een diameter hebben die kleiner is dan de waarde van $D_{v 10}$;

- $\mathrm{D}_{\mathrm{v} 50}[\mu \mathrm{m}]=\mathrm{VMD}[\mu \mathrm{m}]$ (Volume Median Diameter); $50 \%$ van het volume bestaat uit druppels die een diameter hebben die kleiner is dan de waarde van $D_{v 50}$;

- $D_{\text {v9o }}[\mu \mathrm{m}] ; 90 \%$ van het volume bestaat uit druppels die een diameter hebben die kleiner is dan de waarde van $\mathrm{D}_{\mathrm{v} 90}$;

- $\mathrm{V}_{100}[\%]$; volumepercentage van druppels met een diameter kleiner dan $100 \mu \mathrm{m}$;

- $v_{\mathrm{gem}}[\mathrm{m} / \mathrm{s}]$; gemiddelde snelheid van alle gemeten druppels in het meetvlak.

\subsection{Modelberekeningen}

De resultaten van de metingen van de druppelgrootteverdeling en de druppelsnelheden kunnen als invoer in het driftmodel IDEFICS-win (versie 0.434; maart 2020) gebruikt worden. Voor de modelberekeningen met de Airtec Groen en Airtec Blauw spuitdoppen werden slechts enkele combinaties doorgerekend, zoals genoemd in par.3.4. Daarbij waren de volgende instellingen van toepassing:

- plaats van de laatste spuitdop 0,50 m binnen het gewas *

- afstand tussen doppen aan de spuitboom; 0,25 $\mathrm{m} * *$

- achterwaartse kantelhoek van $25^{\circ}$ voor de spuitkegel van de Airtec doppen

- een gewashoogte van 0,50 m;

- rijsnelheid 1,67 m/s (=6,0 km/u);

- rijrichting evenwijdig aan de gewasrand;

- windrichting loodrecht op de gewasrand van het gewas af gericht;

- windsnelheid $3 \mathrm{~m} / \mathrm{s}$ (op $2 \mathrm{~m}$ hoogte);

- relatieve luchtvochtigheid $60 \%$;

- luchttemperatuur $15^{\circ} \mathrm{C}$;

- stabiliteit van de atmosfeer neutraal (geen thermiek).

* De uitgangssituatie was een gewas aardappelen met de laatste rug op 0,75 m van de insteek van de sloot, bij een dopafstand van 0,50 m staat de buitenste spuitdop op 0,125 m buiten het midden van de laatste rug; gewasontwikkeling tot de insteek. Bij de berekeningen met IDEFICS is ter correctie van een aflopende gewasrand de afstand van de laatste dop tot de gewasrand afgerond op 0,50 m (zie Figuur 5).

** voor de modelberekeningen met BCPC-F/M en ISO-F/M doppen was de dopafstand 0,50 m.

De volvelds simulaties zijn in vijfvoud uitgevoerd, met 30.000 druppels per dop, voor 14 doppen verdeeld over een spuitbreedte van $50 \mathrm{~m}$. Door middel van interpolatie en extrapolatie voor niet gesimuleerde doppen is een simulatie van een volvelds bespuiting mogelijk.

De resultaten van de modelberekeningen gaven de depositiewaarden op aaneensluitende strookjes met breedte 0,25 m, gerekend vanaf de gewasrand. Deze resultaten werden bewerkt tot gemiddelde deposities op de strook 2,125-3,125 m vanaf de laatste spuitdop. Dit is de strook waarvoor bij de gekozen uitgangssituatie voor aardappelen het wateroppervlak van de sloot ligt (Huijsmans et al., 1997). 


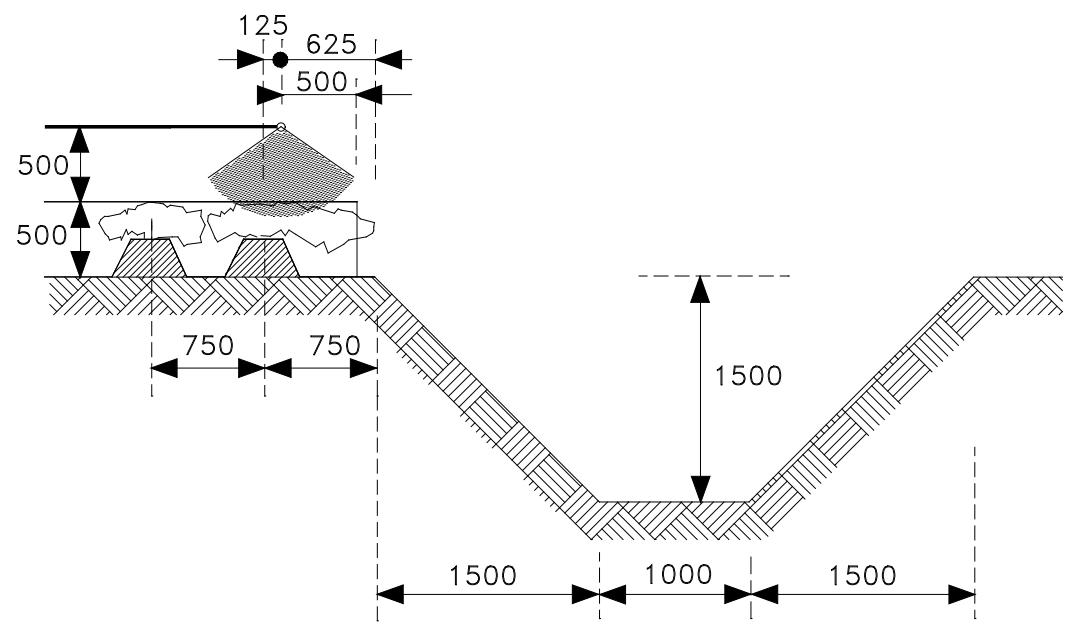

Figuur $5 \quad$ Overzicht van de situatie voor de modelberekeningen bij een gewas aardappelen (afmetingen in $\mathrm{mm}$ ).

De driftreductie is berekend analoog aan de methode van Porskamp et al. (1999) ten opzichte van een referentiedop BCPC F/M en zoals weergegeven in het meetprotocol (I\&W, 2021). Het referentiespectrum is op dezelfde dagen gemeten als waarop de druppelgroottemetingen van de onderzochte Airtec-doppen zijn uitgevoerd.

$\mathrm{Er}$ is enige statistische spreiding te verwachten in zowel het gemiddelde druppelgroottespectrum (wat gevolgen heeft voor de berekende drift) als in de resultaten van de driftberekeningen op zich. Door de herhaalde metingen van druppelgroottespectra en de herhalingen in de driftsimulaties zijn deze onzekerheden sterk te reduceren. Het blijkt dat de onzekerheid in de berekende driftwaarden ongeveer $1 \%$ bedraagt. Hieruit is af te leiden dat bij een driftreductie van $75 \%$ de onzekerheid ca. 0,4\% is, bij $90 \%$ ca. 0,2\% en bij 95\% ca. 0,1\%. Bij de voorgestelde indeling van dop-drukcombinaties in driftreductieklassen is hiermee in deze rapportage geen rekening gehouden. Analoog aan de klassenindelingen in Duitsland (Ganzelmeier en Rautmann, 2000) en Engeland (Gilbert, 2000) en de beoordeling van resultaten van veldproeven (ISO22369, 2006; I\&M, 2017b) is uitgegaan van de absolute waarden 50, 75, 90 en 95\% voor het vastleggen van de grenzen van de reductieklassen. 


\section{Meetresultaten}

\subsection{Vloeistofverdeling van spuitboomconfiguraties}

Op een AAMS spuitbord zijn de verdelingspatronen gemeten van de Airtec NAP06LD 80 Groen en Airtec NAP06LD 80 Blauw doppen bij verschillende combinaties van vloeistofdruk (300, 400 en $500 \mathrm{kPa}$ ) en luchtdruk (60,70, 80 en $100 \mathrm{kPa})$, bij spuitdophoogtes en dopafstand zoals genoemd in paragraaf 2.1. De variatiecoëfficiënt (VC) bij een effectieve gootbreedte van $10 \mathrm{~cm}$ is bepaald over een lengte van $1,00 \mathrm{~m}$. De combinaties met $\mathrm{VC}<10 \%$ en bijbehorende VC staan in Tabel 1 ; alleen combinaties met een spuitdopafstand van 0,25 m bleken hieraan te voldoen.

Deze situaties omvatten 10 combinaties van vloeistof- en luchtdruk, bij enkele instellingen van spuitdophoogte. In een eerste verkenning bleek dat één van de 10 drukcombinaties geen $V_{100}$ op zou leveren die kleiner zou zijn dan de helft van de $\mathrm{V}_{100}$ van de referentiedop BCPC-F/M (en daarmee dus niet als driftreducerende dop zou kunnen worden aangemerkt). Dit was de combinatie Airtec Groen bij $300 \mathrm{kPa}$ vloeistofdruk en $100 \mathrm{kPa}$ luchtdruk. Deze is in Tabel 1 met een ster gemarkeerd en is niet verder onderzocht.

Tabel 1 Variatiecoëfficiënt (VC) van onderzochte combinaties van vloeistofdruk, luchtdruk en spuitdophoogte (h) voor Airtec NAP06LD 80 Groen en Airtec NAP06LD 80 Blauw. Alleen de onderzochte combinaties met VC <10\% zijn weergegeven. Spuitdopafstand is 0,25 m. Bron: opdrachtgever.

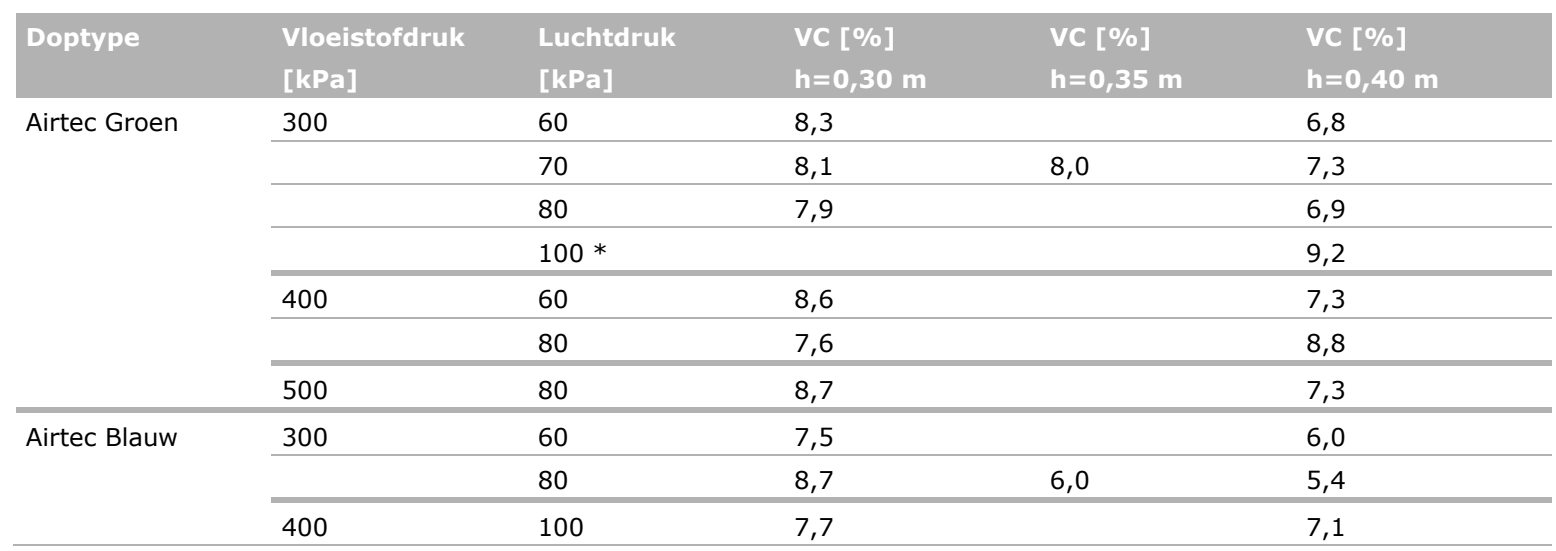

* deze drukcombinatie is niet verder onderzocht omdat de $\mathrm{V}_{100}$ niet voldoende klein was; zie tekst.

\subsection{Vloeistofafgifte}

Tien doppen Airtec Groen en Airtec Blauw werden genummerd en voor elk van deze doppen werd vervolgens de vloeistofafgifte gemeten bij vloeistofdruk van $300 \mathrm{kPa}$ en luchtdruk van $60 \mathrm{kPa}$. De drie doppen met een afgifte het dichtst bij de mediaan werden geselecteerd voor de metingen van de druppelgrootteverdelingen met de PDPA. De gemeten afgifte, mediaan en nummers van de drie geselecteerde doppen staan vermeld in Tabel 2. 
Tabel 2 Afgiftemetingen voor tien doppen Airtec NAP06LD 80 Groen en Airtec NAP06LD 80 Blauw bij een vloeistofdruk van $300 \mathrm{kPa}$ en een luchtdruk van $60 \mathrm{kPa}$. In de laatste twee kolommen zijn de bijbehorende mediaan en de nummers van de drie geselecteerde doppen, waarvan de afgifte het dichtst bij de mediaan ligt, gegeven.

\begin{tabular}{|c|c|c|c|c|c|c|c|c|c|c|c|c|}
\hline \multirow[t]{2}{*}{ Doptype } & \multicolumn{10}{|c|}{ Dopnummers en afgifte $[\mathrm{ml} / \mathrm{min}]$} & \multirow{2}{*}{$\begin{array}{l}\text { mediaan } \\
{[\mathrm{ml} / \mathrm{min}]}\end{array}$} & $\begin{array}{l}\text { gekozen } \\
\text { doppen }\end{array}$ \\
\hline & 1 & 2 & 3 & 4 & 5 & 6 & 7 & 8 & 9 & 10 & & \\
\hline Airtec Blauw & 935,0 & 950,0 & 987,5 & 917,5 & 910,0 & 952,5 & 1005,0 & -1 & 950,0 & 930,0 & 950,0 & 129 \\
\hline
\end{tabular}

\subsection{Druppelgroottespectrum}

Van de 9 resulterende drukcombinaties uit Tabel 1 (na uitsluiting van de combinatie met een te hoge $\mathrm{V}_{100}$ ) zijn druppelgrootteverdelingen gemeten. In Tabel 3 is het gemiddelde van de karakteristieke grootheden voor de geteste Airtec-doppen bij de onderzochte combinaties van vloeistof- en luchtdruk samengevat, zoals bepaald met de PDPA. De bijbehorende metingen van de BCPC-F/M referentiedop als ook van de toekomstige referentiedop ISO-F/M zijn eveneens in deze tabel opgenomen. Van elk van de drie geselecteerde doppen (zie Tabel 2) werd de druppelgrootteverdeling in drievoud gemeten. De meetwaarden van de individuele metingen staan in Bijlage 1. Voor de driftsimulaties met IDEFICS is ook de tophoek van de spuitkegel van belang. Deze is eveneens in Tabel 3 vermeld, ook voor de gevallen waarvoor geen nadere simulaties met IDEFICS zijn uitgevoerd.

Tabel 3 Samenvatting van de karakteristieke grootheden van het druppelgroottespectrum, gemiddelde druppelsnelheid en aantal gemeten druppels voor de Airtec NAP06LD 80 Groen en Airtec NAP06LD 80 Blauw doppen bij verschillende vloeistof- en luchtdrukken. Tevens soortgelijke gegevens voor de referentiedop BCPC F/M, en toekomstige referentiedop ISO-F/M opgenomen. Gemeten met PDPA.

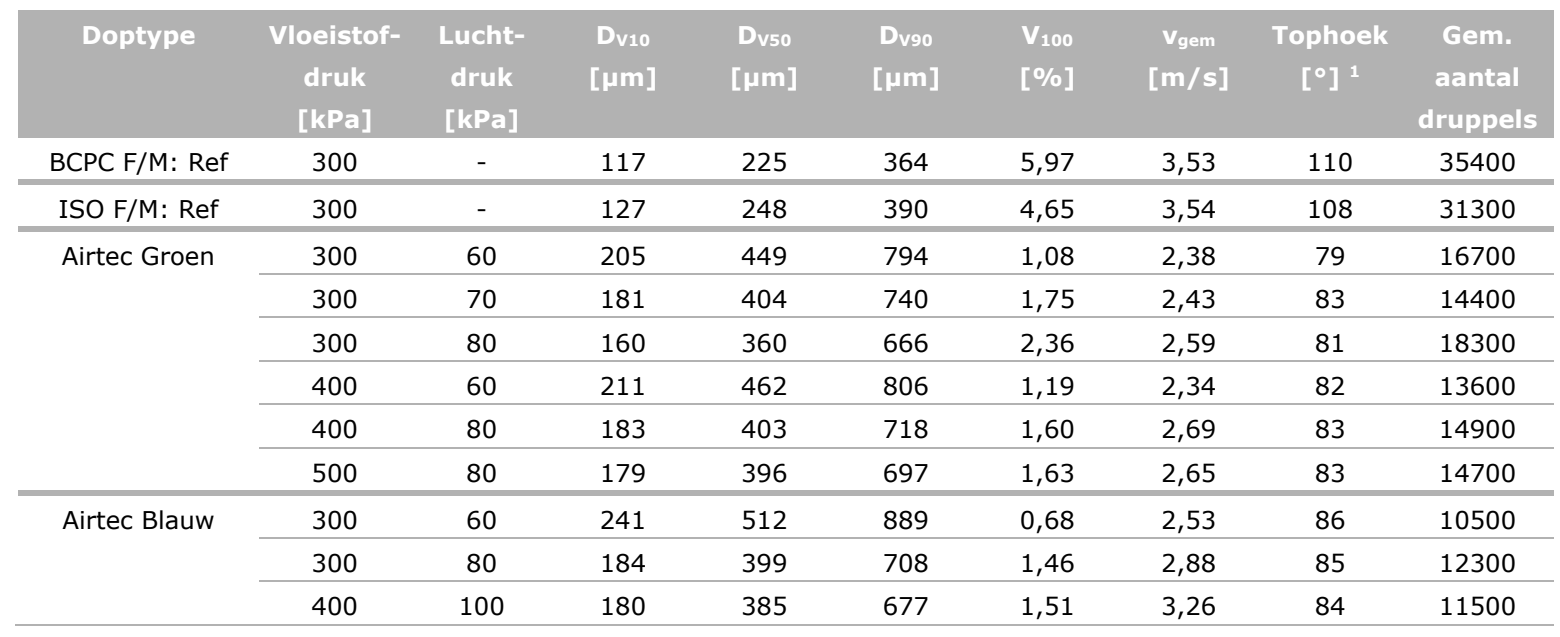

\subsection{Driftdepositie en dopclassificatie}

De $V_{100}$ van de BCPC-F/M referentiedop is 5,97\% (Tabel 3); de helft daarvan is $2,99 \%$. Alle negen geteste combinaties van de Airtec-doppen in Tabel 3 hebben een $V_{100}$ die ruim onder deze waarde van 2,99\% ligt; ze kunnen daarmee in aanmerking komen voor de status 'driftarm', zoals beschreven in het meetprotocol voor het vaststellen van driftreductie van spuitdoppen (I\&W, 2021). 
Uit verkennende berekeningen met IDEFICS kwam naar voren dat naar verwachting de meeste van de situaties uit Tabel 3 niet hoger kunnen komen dan de klasse DRD50. De meeste kans op een driftreductie meer dan 75\% hadden de beide volgende combinaties: Airtec Groen bij $300 \mathrm{kPa}$ vloeistofdruk en 60 kPa luchtdruk en Airtec Blauw bij dezelfde vloeistof- en luchtdruk. Deze beide combinaties werden daarom met IDEFICS doorgerekend voor een volvelds situatie uitgevoerd voor de genoemde vloeistof- en luchtdruk, bij 0,50 m spuitdophoogte en 0,25 m dopafstand. De driftsimulaties zijn in vijfvoud uitgevoerd zowel voor de te testen situaties als voor de referentiesituaties. Vervolgens zijn het gemiddelde en de standaardfout van het gemiddelde (SEM, standard error of mean) van de driftdeposities op de evaluatiestrook bepaald. Deze waarden staan in Tabel 4 vermeld. De gemiddelde driftreductie op de evaluatiestrook is bepaald ten opzichte van de driftdepositie voor een referentiebespuiting met BCPC-F/M doppen. Voor de Airtec Groen is de driftreductie $71 \%$ en voor de Airtec Blauw is dat $79 \%$. De geschatte standaardfout in deze bepalingen is ook aangegeven en bedraagt resp. 0,3 en 0,2\%. Alleen de Airtec Blauw geeft bij de ingestelde drukken een driftreductie van meer dan $75 \%$ op de evaluatiestrook.

De situatie met de potentiële nieuwe referentiedoppen ISO-F/M levert een iets lagere driftdepositie op en daarmee ook een lagere reductie voor de geteste Airtec-doppen: resp. 65,0\% en 75,3\% voor Airtec Groen en Airtec Blauw. Deze waarden staan niet in de tabel vermeld, omdat het huidige meetprotocol van de BCPC-F/M referentiedoppen uitgaat.

Tabel 4 Berekende driftdepositie en driftreducties op de strook 1,625-2,625 m vanaf de gewasrand ${ }^{1}$ voor de Airtec NAP06LD 80 Groen en Airtec NAP06LD 80 Blauw beide bij een vloeistofdruk van $300 \mathrm{kPa}$ en luchtdruk van $60 \mathrm{kPa}$, bij spuitdophoogte 0,50 m en dopafstand 0,25 m. Tevens voor de referentiebespuiting met BCPC-F/M doppen en mogelijk toekomstige ISO-F/M referentiedoppen. In alle gevallen zat de buitenste dop op 0,50 m binnen de gewasrand.

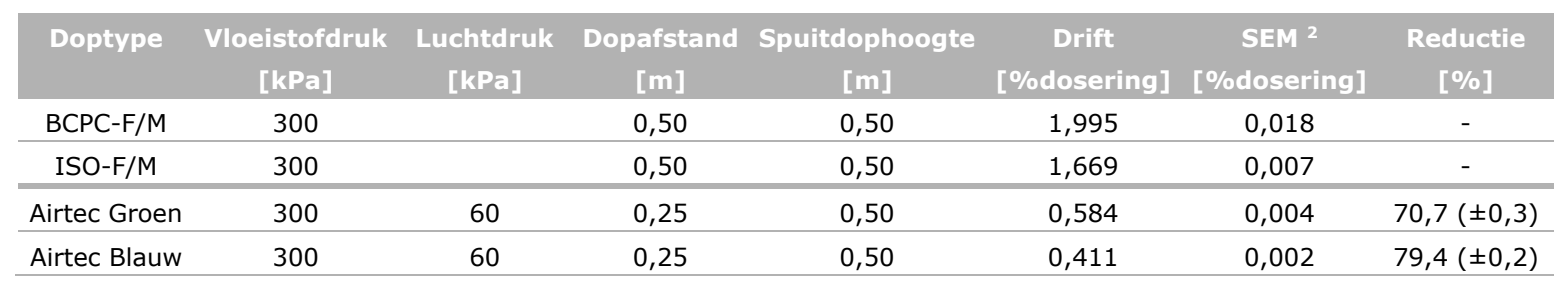

1 dit komt overeen met 2,125-3,125 m vanaf de buitenste dop.

$2 \mathrm{SEM}=$ standard error of mean, rekening houdend met 5 onafhankelijke driftsimulaties in elke situatie. 


\section{$4 \quad$ Conclusie}

Voor de lucht-vloeistofmengdoppen Airtec NAP06LD 80 met groene of blauwe restrictor, nader aangeduid als resp. 'Airtec NAP06LD 80 Groen' en 'Airtec NAP06LD 80 Blauw' zijn druppelgroottemetingen verricht bij verschillende combinaties van vloeistofdruk (300, 400 en $500 \mathrm{kPa}$ ) en luchtdruk $(60,70,80$ en $100 \mathrm{kPa})$. Aan de hand van verdelingsmetingen op een spuitbord is voor een aantal configuraties onderzocht welke combinaties van spuitdophoogte en dopafstand voldeden aan de norm van een variatiecoëfficiënt (VC) kleiner dan 10\%. Dit betrof 10 combinaties met een spuitdophoogte van 0,30, 0,35 of 0,40 m, waarbij de dopafstand steeds $0,25 \mathrm{~m}$ bedroeg. In één van deze 10 situaties bleek de het aandeel kleine druppels te groot om in aanmerking te komen voor classificatie als 'driftarm' (de $\mathrm{V}_{100}$ was namelijk groter dan de helft van de $\mathrm{V}_{100}$ van de referentiedop BCPC-F/M); deze situatie is niet verder onderzocht. Voor de 9 andere situatie is de druppelgrootteverdeling nauwkeurig onderzocht voor 3 geselecteerde doppen, elk in drievoud gemeten; de $\mathrm{V}_{100}$ van deze 9 situaties bleek kleiner dan de helft van de $\mathrm{V}_{100}$ van de referentiedop BCPC-F/M, een voorwaarde om in aanmerking ter komen voor de status 'driftarm' (of ook DRD50 classificatie). Twee van deze situaties zouden mogelijk een driftreductie van meer dan $75 \%$ kunnen opleveren; deze zijn daarom nader onderzocht met het IDEFICS driftmodel, namelijk de Airtec NAP06LD 80 Groen en Airtec NAP06LD 80 Blauw bij 300 kPa vloeistofdruk en 60 kPa luchtdruk. Daarvan werd alleen voor de Airtec NAP06LD 80 Blauw een driftreductie van meer dan 75\% behaald. Bovengenoemde testresultaten zijn samengevat in onderstaande tabel.

Tabel 5 Samenvatting van de testresultaten van negen vloeistof- en luchtdrukcombinaties voor Airtec Groen en Airtec Blauw op basis van $V_{100}$ en simulaties met driftmodel IDEFICS.

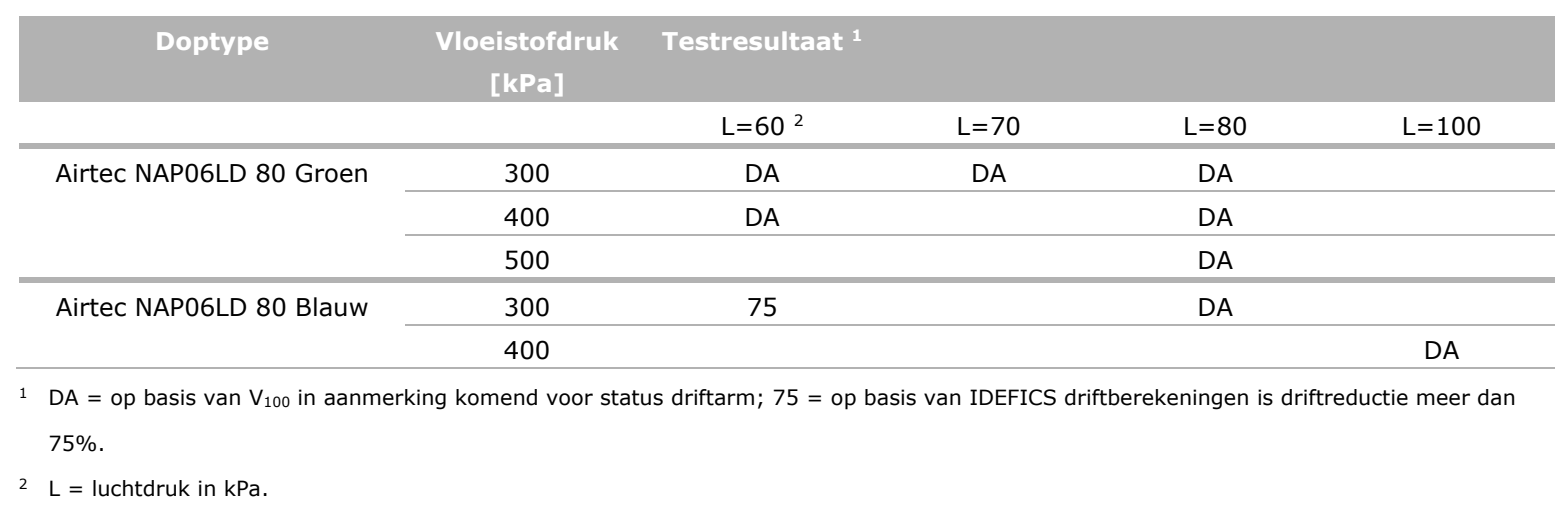




\section{Literatuur}

Ganzelmeier, H. \& Rautmann D., 2000. Drift, drift reducing sprayers and sprayer testing. Aspects of Applied Biology 57, Pesticide application, 2000, p1-10.

Gilbert, A.J., 2000. Local Environmental Risk Assessment for Pesticides (LERAP) in the UK. Aspects of Applied Biology 57, Pesticide Application, 2000, p83-90.

Holterman, H.J., J.C. van de Zande, H.A.J. Porskamp en J.F.M. Huijsmans, 1997. Modelling spray drift from boom sprayers. Computers and Electronics in Agriculture 19(1997): p1-22.

Huijsmans, J.F.M., H.A.J. Porskamp en J.C. van de Zande, 1997. Drift(beperking) bij de toediening van gewasbeschermingsmiddelen. Evaluatie van de drift van spuitvloeistof bij bespuitingen in de fruitteelt, de volveldsteelten en de boomteelt (stand van zaken december 1996). IMAG-DLO Rapport 97-04, IMAG, Wageningen, 38 pp.

I\&M, 2012. Activiteitenbesluit Milieubeheer, Staatsblad 2012 441/643

I\&M, 2017a. Wijziging van het Activiteitenbesluit milieubeheer in verband met de vermindering van emissies van gewasbeschermingsmiddelen in de glastuinbouw en open teelten. Staatsblad 23 juni 2017. 305

I\&M, 2017b. Meetprotocol voor het vaststellen van de driftreductie van neerwaartse en op- en zijwaartse spuittechnieken - versie 1 juli 2017. Op Helpdeskwater.nl.

I\&W, 2021. Meetprotocol voor het vaststellen van de driftreductie van spuitdoppen voor neerwaartse en op- en zijwaartse bespuiting - versie 15 maart 2021. Op Helpdeskwater.nl.

ISO5682-1, 2014. Equipment for crop protection - Spraying equipment - Part 1: Test methods for sprayer nozzles. International Organization for Standardization, Geneva.

ISO5682-2, 2017. Equipment for crop protection - Spraying equipment - Part 2: Test methods to assess the horizontal transverse distribution for hydraulic sprayers. International Organization for Standardization, Geneva.

ISO16122-2, 2015. Agricultural and forestry machinery - Inspection of sprayers in use - Part 2: Horizontal boom sprayers. International Organization for Standardization, Geneva.

ISO22369, 2006. Crop protection equipment - Drift classification of spraying equipment. Part 1. Classes. International Organization for Standardization, Geneva.

ISO25358, 2018. Crop protection equipment - Droplet-size spectra from atomizers - Measurement and classification. International Organization for Standardization, Geneva.

Porskamp, H.A.J., J.C. van de Zande, H.J. Holterman en J.F.M. Huijsmans, 1999. Opzet van een classificatiesysteem voor spuitdoppen op basis van driftgevoeligheid. IMAG-DLO Rapport 99-02, IMAG, Wageningen, $22 \mathrm{pp}$.

Southcombe, E.S.E., P.C.H. Miller, H. Ganzelmeier, J.C. van de Zande, A. Miralles \& A.J. Hewitt, 1997. The international (BCPC) spray classification system including a drift potential factor. Proceedings of the Brighton Crop Protection Conference - Weeds, 1997. November 1997. Brighton. UK. p.371-380.

TCT, 2017. Beoordelingssystematiek emissiereducerende maatregelen open teelt. Op Helpdeskwater.nl.

TCT, 2021a. Lijst met indeling van spuitdoppen in DriftReducerende Dop-klassen (DRD-klassen). DRDlijst. Op Helpdeskwater.nl. Versie 22 juli 2021.

TCT, 2021b. Lijst met indeling van spuittechnieken in DriftReducerende Techniek-klassen (DRTklassen). DRT-lijst. Op Helpdeskwater.nl. Versie 7 juni 2021. 


\section{Bijlage 1 Overzicht metingen van druppelgroottes}

In Tabel B. 1 is een overzicht gegeven van druppelgroottemetingen voor de referentiedop BCPC F/M, zoals uitgevoerd op de dagen waarop ook de Airtec-doppen werden gemeten. Deze 12 referentiemetingen zijn samengevoegd tot het druppelgroottespectrum voor de BCPC F/M referentiedop om te gebruiken in de IDEFICS simulaties.

Evenzo is in Tabel B.2 een overzicht gegeven van druppelgroottemetingen voor de potentiële toekomstige referentiedop ISO F/M, eveneens uitgevoerd op de bovengenoemde dagen.

In Tabel B.3 staat een overzicht van de individuele druppelgroottemetingen voor de Airtec NAP06LD 80 Groen. Ten slotte volgt in Tabel B.4 een overzicht van de metingen voor de Airtec NAP06LD 80 Blauw doppen.

Tabel B.1 Overzicht van de karakteristieke grootheden van het druppelgroottespectrum, gemiddelde druppelsnelheid en aantal gemeten druppels voor de BCPC-F/M referentiedop bij 300 kPa vloeistofdruk; gemeten met PDPA gedurende de dagen dat ook de te onderzoeken doppen werden gemeten.

\begin{tabular}{cccccccc} 
Run & Datum & $\begin{array}{c}\text { Dv10 } \\
{[\mu \mathrm{m}]}\end{array}$ & $\begin{array}{c}\text { Dv50 } \\
{[\mu \mathrm{m}]}\end{array}$ & $\begin{array}{c}\text { Dvgo } \\
{[\mu \mathrm{m}]}\end{array}$ & $\begin{array}{c}\mathrm{V}_{100} \\
{[\%]}\end{array}$ & $\begin{array}{c}\mathrm{V}_{\mathrm{gem}} \\
{[\mathrm{m} / \mathrm{s}]}\end{array}$ & $\begin{array}{c}\text { Aantal } \\
\text { druppels }\end{array}$ \\
\hline 1 & $14-5-2021$ & 116.3 & 222.7 & 353.8 & 5.98 & 3.53 & 34300 \\
\hline 2 & & 116.8 & 225.5 & 362.5 & 5.99 & 3.56 & 35000 \\
\hline 3 & & 118.7 & 224.6 & 365.5 & 5.53 & 3.53 & 33500 \\
\hline 4 & $21-5-2021$ & 116.8 & 225.3 & 366.3 & 5.94 & 3.55 & 35400 \\
\hline 5 & & 115.8 & 225.4 & 361.4 & 6.20 & 3.54 & 36400 \\
\hline 6 & & 117.8 & 225.8 & 368.3 & 5.73 & 3.49 & 35400 \\
\hline 7 & $1-6-2021$ & 116.9 & 228.1 & 370.9 & 6.00 & 3.64 & 35500 \\
\hline 8 & & 118.2 & 226.2 & 371.2 & 5.78 & 3.64 & 34000 \\
\hline 9 & & 115.7 & 223.9 & 374.2 & 6.11 & 3.48 & 36600 \\
\hline 10 & $8-6-2021$ & 115.6 & 224.3 & 369.1 & 6.13 & 3.45 & 36300 \\
\hline 11 & & 115.5 & 223.7 & 355.1 & 6.13 & 3.41 & 37000 \\
\hline 12 & & 115.9 & 222.0 & 353.1 & 6.12 & 3.51 & 35400 \\
\hline
\end{tabular}

Tabel B.2 Overzicht van de karakteristieke grootheden van het druppelgroottespectrum, gemiddelde druppelsnelheid en aantal gemeten druppels voor de ISO-F/M referentiedop bij $300 \mathrm{kPa}$ vloeistofdruk; gemeten met PDPA gedurende de dagen dat ook de te onderzoeken doppen werden gemeten.

\begin{tabular}{cccccccc} 
Run & Datum & $\begin{array}{c}\text { Dv10 } \\
{[\mu \mathrm{m}]}\end{array}$ & $\begin{array}{c}\text { Dv50 } \\
{[\mu \mathrm{m}]}\end{array}$ & $\begin{array}{c}\text { Dv90 } \\
{[\mu \mathrm{m}]}\end{array}$ & $\begin{array}{c}\mathrm{V}_{100} \\
{[\%]}\end{array}$ & $\begin{array}{c}\mathrm{V}_{\mathrm{gem}} \\
{[\mathrm{m} / \mathrm{s}]}\end{array}$ & $\begin{array}{c}\text { Aantal } \\
\text { druppels }\end{array}$ \\
\hline 1 & $14-5-2021$ & 126.2 & 246.8 & 388.4 & 4.76 & 3.59 & 32300 \\
\hline 2 & & 130.1 & 249.6 & 394.4 & 4.28 & 3.61 & 30200 \\
\hline 3 & & 125.3 & 246.9 & 398.1 & 4.86 & 3.44 & 34300 \\
\hline 4 & $21-5-2021$ & 127.0 & 250.9 & 402.7 & 4.68 & 3.52 & 31000 \\
\hline 5 & & 127.4 & 249.7 & 390.6 & 4.65 & 3.58 & 31800 \\
\hline 6 & & 126.1 & 249.8 & 388.8 & 4.84 & 3.54 & 30600 \\
\hline 7 & $1-6-2021$ & 124.9 & 245.3 & 390.1 & 4.95 & 3.55 & 30800 \\
\hline 8 & & 129.2 & 247.5 & 389.6 & 4.29 & 3.54 & 29200 \\
\hline 9 & & 127.1 & 244.7 & 386.1 & 4.60 & 3.58 & 31300 \\
\hline 10 & $8-6-2021$ & 127.4 & 248.3 & 387.5 & 4.64 & 3.46 & 31600 \\
\hline 11 & & 128.5 & 251.2 & 386.1 & 4.49 & 3.54 & 30600 \\
\hline 12 & & 126.5 & 246.6 & 381.6 & 4.72 & 3.49 & 31800 \\
\hline & gemiddeld & $\mathbf{1 2 7 . 1}$ & $\mathbf{2 4 8 . 1}$ & $\mathbf{3 9 0 . 3}$ & $\mathbf{4 . 6 5}$ & $\mathbf{3 . 5 4}$ & $\mathbf{3 1 3 0 0}$ \\
\hline
\end{tabular}


Tabel B.3 Overzicht van de karakteristieke grootheden van het druppelgroottespectrum, gemiddelde druppelsnelheid en aantal gemeten druppels voor de Airtec NAPO6LD 80 Groen bij een vloeistofdruk van 300, 400 en $500 \mathrm{kPa}$ en luchtdruk van 60, 70 en $80 \mathrm{kPa}$; alleen voor drukcombinaties waarvoor op een spuitbord de VC $<10 \%$ was.

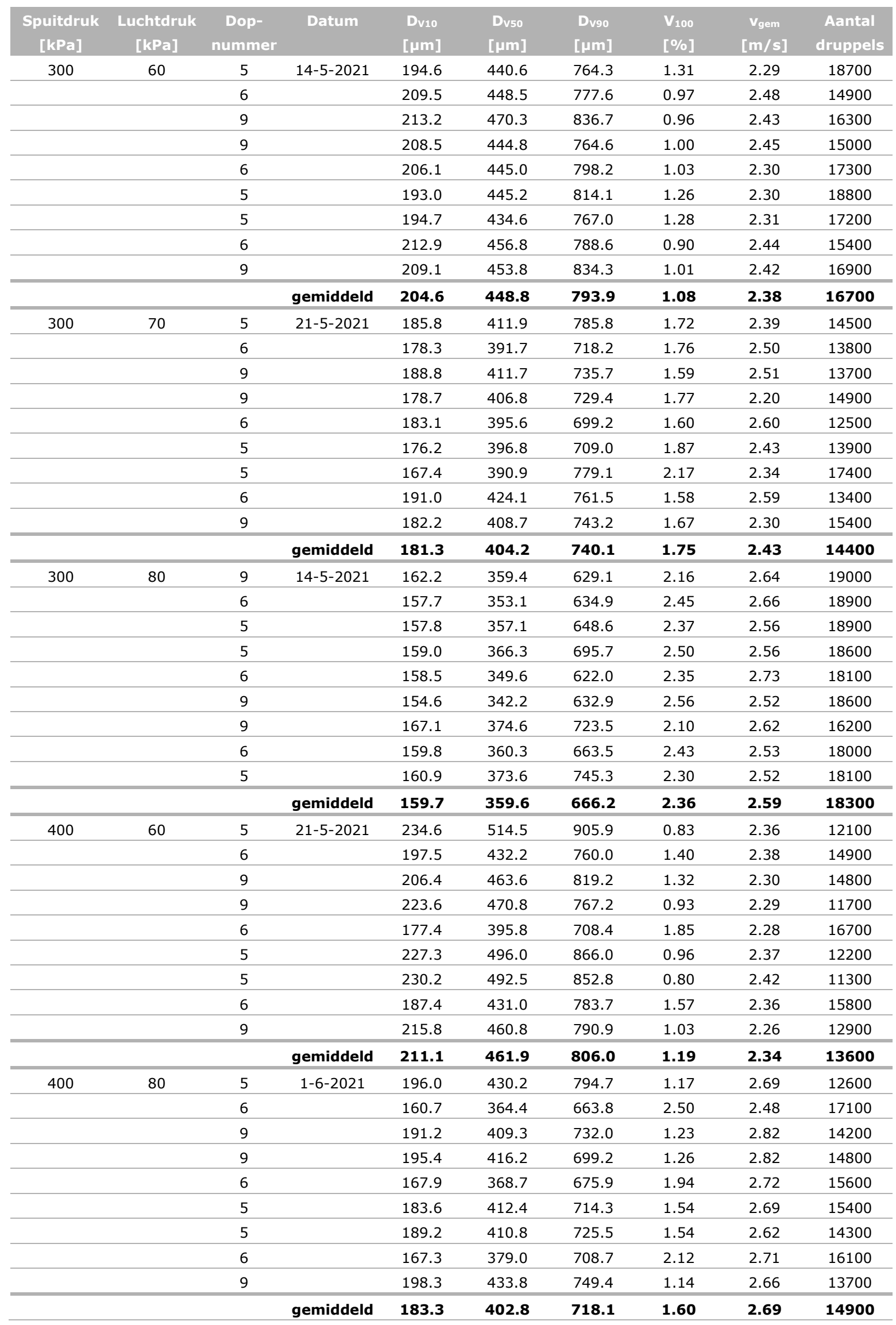


Tabel B.3 (vervolg)

\begin{tabular}{|c|c|c|c|c|c|c|c|c|c|}
\hline $\begin{array}{c}\text { Spuitdruk } \\
\text { [kPa] }\end{array}$ & $\begin{array}{c}\text { Luchtdruk } \\
\text { [kPa] }\end{array}$ & $\begin{array}{c}\text { Dop- } \\
\text { nummer }\end{array}$ & Datum & $\begin{array}{l}\text { Dv10 } \\
{[\mu \mathrm{m}]}\end{array}$ & $\begin{array}{l}\text { Dv50 } \\
\text { [ } \mu \mathrm{m}]\end{array}$ & 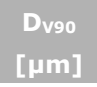 & $\begin{array}{l}V_{100} \\
{[\%]}\end{array}$ & $\begin{array}{c}V_{g e m} \\
{[\mathrm{~m} / \mathrm{s}]}\end{array}$ & $\begin{array}{l}\text { Aantal } \\
\text { druppels }\end{array}$ \\
\hline \multirow[t]{7}{*}{500} & 80 & 9 & $1-6-2021$ & 185.3 & 409.9 & 744.2 & 1.44 & 2.54 & 14400 \\
\hline & & 5 & & 179.0 & 394.6 & 668.7 & 1.55 & 2.71 & 13700 \\
\hline & & 5 & & 187.0 & 412.4 & 717.8 & 1.45 & 2.67 & 14000 \\
\hline & & 9 & & 187.7 & 420.3 & 789.9 & 1.53 & 2.55 & 15400 \\
\hline & & 9 & & 183.4 & 411.3 & 761.2 & 1.45 & 2.48 & 14900 \\
\hline & & 6 & & 172.7 & 372.1 & 623.8 & 1.64 & 2.71 & 14100 \\
\hline & & 5 & & 182.9 & 396.2 & 677.2 & 1.51 & 2.78 & 13300 \\
\hline
\end{tabular}

Tabel B.4 Overzicht van de karakteristieke grootheden van het druppelgroottespectrum, gemiddelde druppelsnelheid en aantal gemeten druppels voor de Airtec NAP06LD 80 Blauw bij een vloeistofdruk van 300 en 400 kPa en luchtdruk van 60, 80 en 100 kPa; alleen voor drukcombinaties waarvoor op een spuitbord de $\mathrm{VC}<10 \%$ was.

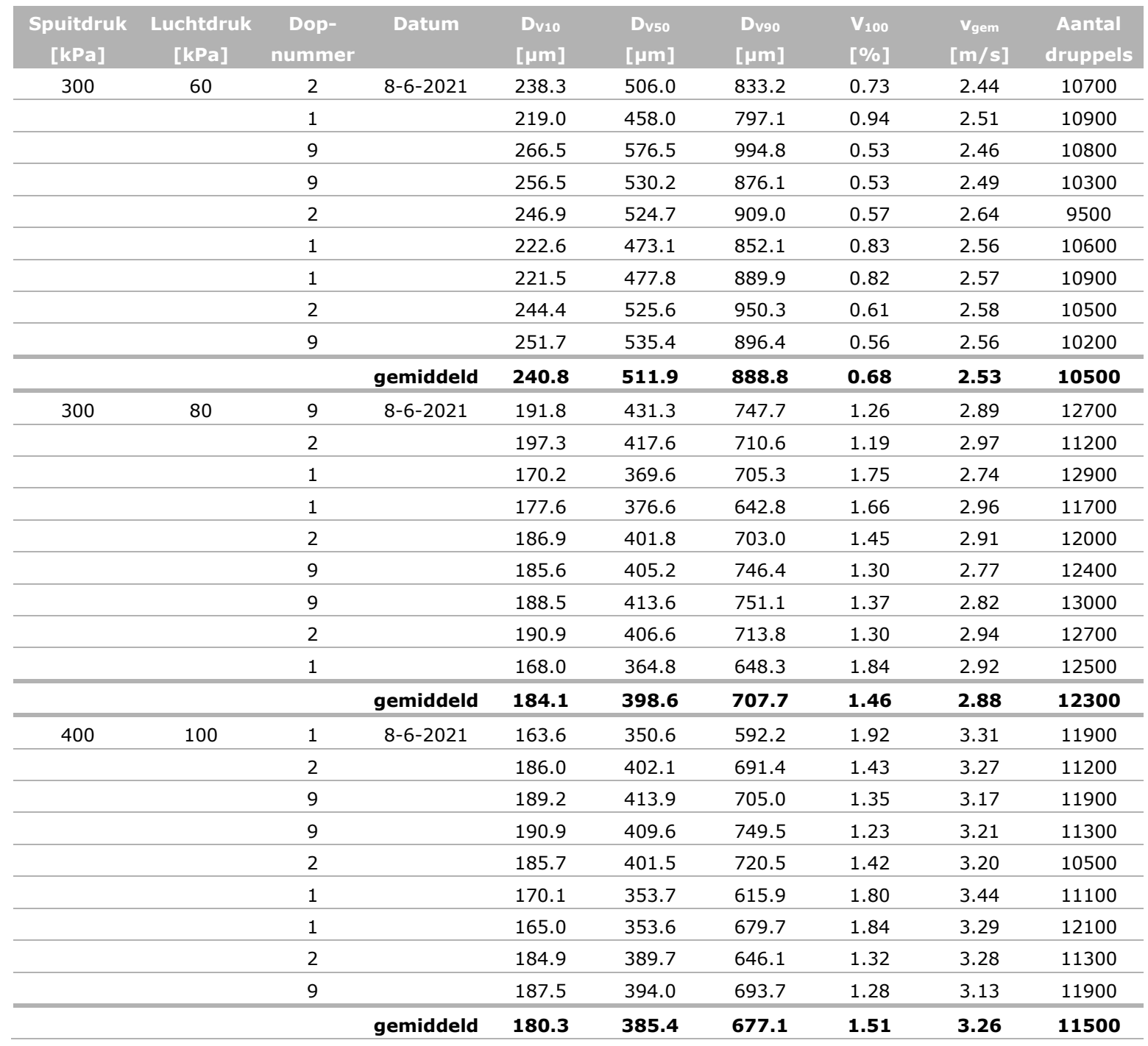


Correspondentie adres voor dit rapport: Postbus 16

6700 AA Wageningen

T 0317480700

www.wur.nl/plant-research

Rapport WPR-1097
De missie van Wageningen University \& Research is 'To explore the potential of nature to improve the quality of life'. Binnen Wageningen University \& Research bundelen Wageningen University en gespecialiseerde onderzoeksinstituten van Stichting Wageningen Research hun krachten om bij te dragen aan de oplossing van belangrijke vragen in het domein van gezonde voeding en leefomgeving. Met ongeveer 30 vestigingen, 6.800 medewerkers ( $6.000 \mathrm{fte}$ ) en 12.900 studenten behoort Wageningen University \& Research wereldwijd tot de aansprekende kennisinstellingen binnen haar domein. De integrale benadering van de vraagstukken en de samenwerking tussen verschillende disciplines vormen het hart van de unieke Wageningen aanpak. 



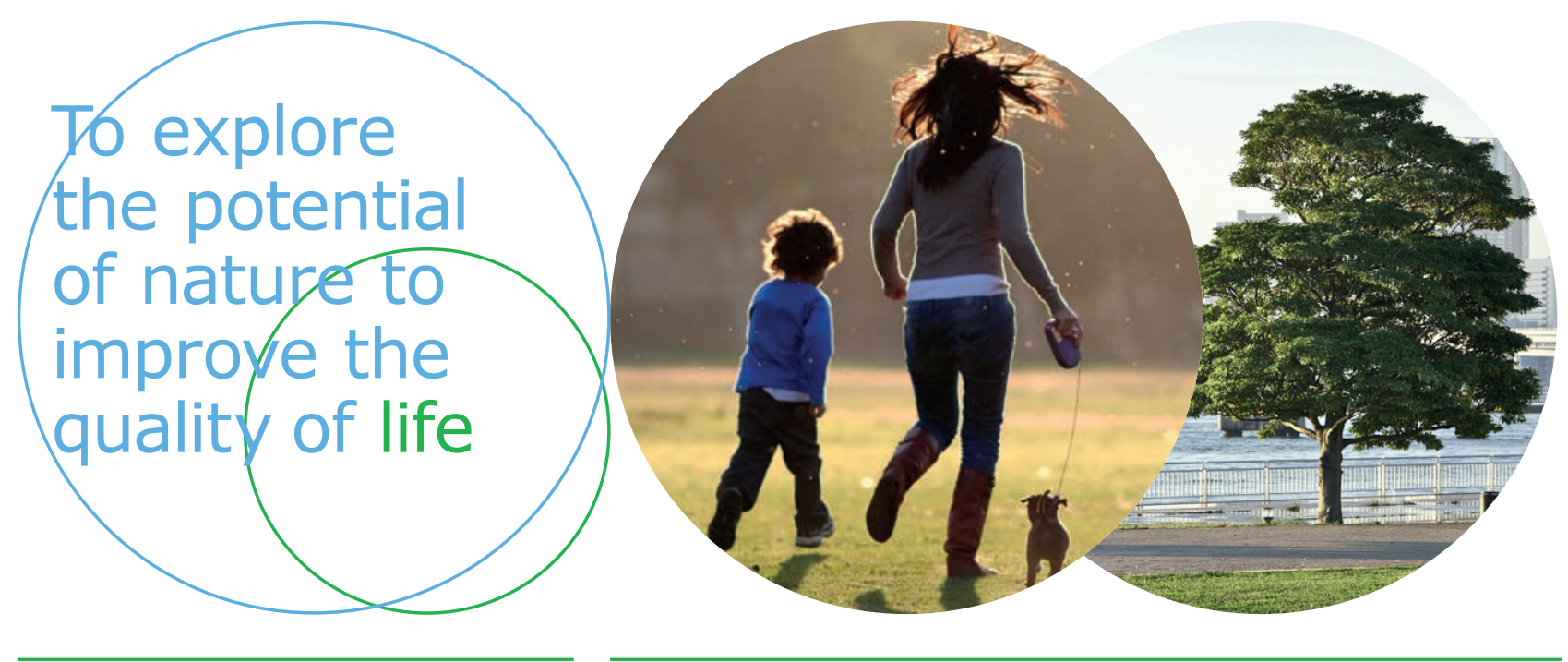

Correspondentie adres voor dit rapport: Postbus 16

6700 AA Wageningen

T 0317480700

www.wur.nl/plant-research

Rapport WPR-1097
De missie van Wageningen University \& Research is 'To explore the potential of nature to improve the quality of life'. Binnen Wageningen University \& Research bundelen Wageningen University en gespecialiseerde onderzoeksinstituten van Stichting Wageningen Research hun krachten om bij te dragen aan de oplossing van belangrijke vragen in het domein van gezonde voeding en leefomgeving. Met ongeveer 30 vestigingen, 6.800 medewerkers ( $6.000 \mathrm{fte}$ ) en 12.900 studenten behoort Wageningen University \& Research wereldwijd tot de aansprekende kennisinstellingen binnen haar domein. De integrale benadering van de vraagstukken en de samenwerking tussen verschillende disciplines vormen het hart van de unieke Wageningen aanpak. 